\title{
Research on Financial Supervision Under the Condition of Financial Opening to the Outside World
}

\author{
Chen Xiaoying ${ }^{1, \mathrm{a}}$
}

\author{
${ }^{1}$ GuiZhou University of Finance and Economics, Guiyang, Guizhou, China \\ asmallwin124@163.com
}

\begin{abstract}
Financial opening to the outside world is the only way for China to prosper and prosper, and it is also one of the characteristics that a country must have, and it is a manifestation of a country's comprehensive international capabilities. In recent years, China's financial industry has opened more and more to the outside world, especially the opening of the Boao Forum in 2018, which means that a new round of China's financial industry opening to the outside world is officially on the agenda. However, to expand the opening up of the financial industry, financial supervision must closely follow, otherwise the expansion of the scope of supervision and the more complex financial organization structure brought about by financial opening will further increase financial risks and cause turbulence in the international financial industry. This article combines literature and theory with practical methods to study the current situation of China's financial industry opening up and financial supervision, the characteristics and existing problems of financial supervision, and finally put forward relevant suggestions, aiming to create benefits for the new round of financial industry opening up.
\end{abstract}

Keywords: Financial industry, Opening to the outside world, Financial supervision

\section{金融对外开放条件下金融监管问题研究}

\author{
陈晓莹 1, a
}

${ }^{1}$ 贵州财经大学, 贵阳, 贵州, 中国
${ }^{a}$ smallwin124@163.com

\section{摘要}

金融对外开放是中国繁荣昌盛的必经之路，也是一个国家必须具有的特色之一，更是一国国际综合能力的表 现。近几年来，中国金融业对外开放的程度越来越大，特别是 2018 年博鳌论坛的召开，意味着中国新一轮金 融业对外开放正式提上议程。但是，扩大金融业对外开放，金融监管必须紧紧跟上，否则金融开放带来的监管 范围扩大、金融组织结构更为复杂等情形会进一步加大金融风险, 造成国际金融行业的动荡。本文通过文献和 理论结合实际的方法，对中国金融业对外开放和金融监管的现状、金融监管的特点和存在的问题进行研究，最 后提出相关建议，旨在为新一轮金融业对外开放创造有利的条件。

关键词：金融业，对外开放，金融监管

\section{1. 引言}

金融对外开放一直都是国际上的一大热点话题, 2018 年也是新一轮金融开放的开始; 金融是国民经济 的命脉, 而金融监管又是金融体制中最为重要的元素 之一, 研究金融对外开放下中国金融监管的问题具有 十分重要的意义。金融业的对外开放, 不仅能给中国 经济金融带来发展, 而且还增强了国际竞争力。但不 可否认, 金融对外开放也加大了国内金融业在资金和 人才等方面的竞争, 给中国金融业带来更多的复杂性, 增加了一定的运营风险, 不仅使得金融监管的范围扩 大, 也使得监管的对象错综复杂, 而中国金融监管自
身存在的问题也总是不能很好的管控对外开放带来 的风险。为了更好地响应 “十三五” 规划和博鳌亚洲 论坛政策，大力施行对外开放的同时严格防范风险， 我们就必须研究出金融对外开放下中国金融监管存 在的一系列问题，提出对应的政策建议，加大金融监 管，更好地防范金融危机的出现，为中国实现全面对 外开放提供强有力的支持。

王薇（2008）指出：国外混业监管模式给中国金 融分业监管带来了很多压力, 提出了要转变监管观念、 加强国际合作和协调机制并完善监管立法对策。彭涌 （2010）针对金融全球化背景下，提出中国金融监管 
应该从以下几个方面改进: 完善金融市场法律法规; 改变国际金融监管模式; 增强监管机构之间的协调。 严海波（2018）探索出发展中国家多次发生金融危机 的根本核心是放松政府金融管制。也提出了发展中国 家金融业脱离实体经济、获得不正常的超额利润而导 致对金融开放适应性减弱的观点。李树启等（2018） 强调: 金融监管的水平和措施直接决定了金融开放的 程度和进程。刘宏海等（2018）提出金融对外开放对 传统金融监管的挑战有: 金融对外开放扩大了金融监 管信息不对称，扩大国际金融监管空白和国际监管协 调困难。李金智 (2018) 通过对其他国家金融监管体 制的实施的现状进行对比, 提出了要加强央行监管职 权, 将 “二会” 并入央行的政策建议。王德伦 (2019) 从证券市场的角度分析出金融对外开放给中国金融 业带来很多的挑战, 从而号召中国必须要加强对金融 业的监管, 避免出现危机。谭小芬、梁雅慧 (2019) 提出在中国金融开放新形势下, 要加强国际间监管合 作，强化信息披露; 在放松对外资金融机构金融的门 槛的同时, 要加强对事前甄别和事中的监控。邓思成 （2019）提出中国实行双峰监管可以是 “央行+国务 院金融稳定发展委员会” 的模式, 表明央行在金融监 管体系中的地位应该得到提升。

中国的金融监管体制还是分业监管的模式, 而国 内的发展和国际上的压力要求中国必须渐渐实行金 融业全面对外开放，这就使得中国在对外开放下，金 融监管会产生诸多的矛盾和冲击。其次，国内金融对 外开放政策的加大主要是在 2018 年博鳌论坛一事开 始的, 国内在此背景下, 不仅研究金融对外开放与风 险之间的关系, 对金融监管的研究也逐渐加大, 更是 指出了我国当前金融监管体制存在的不足和改进措 施。但是通过对大量文献进行整理发现: 国内在对金 融监管进行研究时, 提出的对策大多具有滞后性、相 似性, 较少结合科技学科进行研究, 这与当代数字时 代的发展是不协同的。

\section{2. 中国金融业对外开放现状}

金融业对外开放以来, 特别是 2018 年新一轮金 融开放以来，中国金融业货币资产得到了很大的进步。 截止 2018 年底, 金融机构资产总额达到 268.24 万亿 元, 同比增长 $6.27 \%$, 负债总额为 246.58 万亿元, 同 比增长 $5.89 \%$, 保险业资产总额为 18.33 万亿元, 同 比增长 $9.45 \%$, 证券业资产总额达到 6.26 万亿元, 同 比增长 $1.95 \%$ 。资产和负债总额的大幅度增加, 不仅 证明了中国实行金融业对外开放是一项正确决策, 也 给今后金融业的发展奠定了基础。

\section{1. 银行业}

在党的十九大会议和博鳌论坛上, 提出加大金融 业对外开放力度的号召, 这是一轮不同于以前的举措。 在银行业方面, 为其代表的是外资银行方面的政策部 署和在中国金融市场的占有率有了极大的变化。截至 2019 年 10 月末, 外资银行在华共设立了 41 家外资
法人银行、114 家母行直属分行和 151 家代表处, 外 资银行营业机构总数达到了 976 家。

\section{2. 证券业}

金融业开放举措得到国际机构纷纷响应, 在 2018 年博鳌论坛后易纲行长宣布的 11 条金融业开放措施 中，特别针对证券业对外开放提出了 4 条。受 2018 年经济运行和中美贸易摩擦的影响，中国合格境外投 资者数目仅从 2017 年的 305 上升到 308 ，截止 2019 年底, 中国 QFII 数目达到 316 家。尽管经济出现低 迷，但随着对外开放措施的进行，中国证券市场上依 旧很快出现了 “阳光”，境内外上市公司数目依旧没 有收到影响, 甚至境外上市公司 (H 股) 数目仍呈上 涨趋势。

证券业作为金融市场中核心部分之一，其股票市 场总能代表着一个国家经济运行情况, 甚至一些专家 称股票行情的走势是一个国家经济趋势的晴雨表。尽 管 2017-2018 年中国境内上市外资公司数目呈现了 下降趋势、股票市值出现了贬值，但 $\mathrm{H}$ 股的上涨又在 一定程度上说明了经济形势的减弱, 也不能阻止中国 证券业对外开放的脚步，资本市场中证券投资基金和 期货成交量依旧呈上升的状态更是提供了证据。

\section{3. 保险业}

在中国金融业实行对外开放的进程中，最早实行 的就是保险业,在 2018 和 2019 年金融业对外开放的 政策中，保险业也是受惠最大的行业。不同金融开放 的政策实施，仿佛将外资机构视为国内的金融机构, 在其设立分支机构时, 除了必要的谨慎监管外, 与国 民享受着同样的待遇。中国大量的保险监管政策, 都 使得外资机构进入中国市场有着很大的优势，从而推 动外资保险的发展, 扩大市场份额, 也达到了保险业 对外开放的目的。

\section{3. 中国金融监管的特点及存在问题}

\section{1. 信息革命给传统金融方式提出了挑战}

随着网络、电子商务等技术的迅速发展, 网络银 行在世界各地都怦然生长。网络银行不比传统的银行, 他营运成本低、操作时间短, 并且可以跨时间、跨空 间地进行交易, 可以在全球各地低成本扩张。然而, 这种没有形体的网络银行, 交易系统复杂、结算数量、 速度大，一旦出现结算错误或者非法交易，涉及的将 是整个网络银行系统, 轻者废掉部分修理费, 重者可 分分钟造成巨大损失, 网络㿈疾。所以, 如何对网上 跨境、跨时间的交易等金融活动进行监管，将是国际 金融监管研究中的一个重大课题。 


\section{2. 协调机制有待健全}

全国没有建立统一的监管协调机制, 独立的中国 金融监管体制很难适应金融业的对外开放。当前中国 的金融监管不仅存在国内各政府监管机构与各行业 协会之间存在不协调现象，在国际上更是与各国没有 统一的协调机制应对金融业开放。由于中国新一轮的 金融业开放时间有限，与国外金融监管机构的交流尚 不充分, 各国金融体系存在千差万别, 比如不同国家 的货币政策、财政政策、贸易政策都在分化，这无疑 进一步加深了金融监管协调的难度, 给金融业开放带 来了更多的不确定性。

\section{3. 外国混业监管带来的压力}

截止到 2002 年年底, 全球至少有 46 个国家已采 取了统一监管模式。随着大量国家实行混业监管, 跨 国金融机构大幅度增加, 金融业务错综复杂, 国与国 之间界限日益模糊, 全球统一化趋势也日渐明朗, 这 无疑给中国分业监管的模式提出了挑战: 若中国不实 行混业经营, 就很难顺利施行金融开放、进行合理的 金融监管、避免全球性金融危机的发生。

\section{4. 监管理念及监管政策的滞后性}

理念是一种在实践中不断探索、发现，从而产生 的一种真理, 是金融监管者首先要具备的本领。一种 正确的监管理念, 是监管者结合历史背景从而对未来 发展趋势的预测, 从而随之制定适宜甚至超前的监管 政策。长期以来, 我国金融监管工作中存在种种落后 的监管理念，在利益与风险面前，监管者往往对风险 的把控力度是不足的, 他们甚至会为了自己机构的利 益, 从而将对自己不利的消息 “隐藏” 起来, 使公众 产生逆向选择的行为。

金融业进一步对外开放可以增加竞争，使中国金 融市场产生新的活力, 经济全球化的发展, 更是暗示 着金融业实行对外开放是一种必然的趋势。2018 年新 的一轮金融业对外开放, 使得中国走出去的步伐越来 越快，但查阅大量监管政策，可以发现针对金融业对 外开放的金融监管政策并没有与开放政策同步, 特别 是从银保监会和证监会监管的现状来看, 监管政策还 存在不完善、监管措施实施较少的特点。

\section{4. 金融对外开放条件下金融监管问题研究}

可以说, 中国金融业对外开放可以给国内带来很 多的机遇，促进金融业发展的同时还能更好的带动中 国经济的发展，但不可否认，金融对外开放的同时， 也会给中国金融业带来更多的风险。在信息不对称下， 一国资产价格的增长, 引起国际短期资本大规模自由 流动, 金融市场不确定增大。脆弱性一旦被放大, 国 外机构纷纷撤资, 从而引发金融市场振荡。此外, 发 达经济体货币政策进程不确定性增大, 亦可能加剧金 融市场波动。金融危机的加大，也增加了金融监管的
难度。金融危机的广泛性、不确定性与复杂性，延伸 了金融监管的时空距离, 使得金融监管传导时效发生 改变, 失去监管的意义与效果。

\section{1. 监管对象的复杂性}

从监管范围方面来看, 金融业进一步地实行改革 开放，监管范围从原本的国内监管转化为对国际方向 的监管。国际金融机构有着庞大的金融运行系统，并 且在全国各地都有业务，以中国为例，现存的金融监 管政策是很难对外资金融机构和国内的跨出去的机 构进行业务方面的监管与考核, 即使可以从别的国家 获得监管资讯，但由于存在信息不对称，也很难对监 管信息进行深层次的挖掘，发现有用的、核心的信息。

从监管机构数目和业务方面看, 由于政策大力鼓 励外资机构金融进入中国市场，或者与中国金融机构 进行合资开展业务，这会给中国金融监管者带来更多 的复杂性，监管对象会在短时间内快速增加，并且运 行模式及组织构架都会相应进行变革, 并且引入国外 金融技术和产品，会给金融监管带来更大的困难与挑 战。

\section{2. 金融创新加大了监管难度}

由于金融市场自由化、对开放的程度加快，使得 国际资金的结构和流向、金融业务都会发生翻天覆地 的变化。随着金融市场的快速发展，跨金融行业、跨 国的金融产品不断涌出，使得传统的业务间隙变得越 来越模糊，金融混业经营的模式越来越凸显。其次， 金融机构为了规避风险，不断从监管空隙中创新产品， 通过各种创新工具和业务把风险转移给愿意承担风 险的一方，从全局上来看，这样仅仅使风险从一方转 移到另一方，结构变得越复杂，但风险并未减少。具 体而言，金融机构通过衍生工具的方式，把资产价格、 利率、汇率等产物进行反复交易，将有关参与者之间 的关系复杂化, 给金融监管带来了更多的复杂性和难 度。

\section{3. 金融业开放对放松监管的呼吁与实际金 融风险加大之间的矛盾}

1973 年，金融抑制论和金融深化论的提出，证明 了政府对金融业的过度干预会减低金融业发展效率， 金融业实行金融对外开放，目的就是带动金融业的发 展，这也从侧面反映了对放松金融监管的呼吁。在 2018 年金融开放的条例和时间表中, 外资保险机构在 某些方面的持股比例大大放松，甚至从 $51 \%$ 提高至 $100 \%$; 其次, 对外来银行的种种业务也纷纷放松了审 批流程要求。布庸置疑, 放松了对外资参股份额和审 批流程的要求, 这样可以使中国金融业市场吸收更多 优秀的外资保险机构, 也有利于在华外资企业在服务 和业务方面 “走出去”。 
放松金融监管有利于实行金融业对外开放, 但放 松对金融业的监管, 也加剧了金融行业的不确定性和 不稳定性。比如在 2008 年, 最先施行金融自由化的 美国过度追求金融自由、追求快速发展，从而忽略对 风险的防控、对金融机构的监管，形成金融泡沫，最 终导致全球性金融危机。

为了更好地实行金融业对外开放，放松部分监管 指标是一个必要的举措, 但放松监管对加大的金融风 险之间是存在着一定的矛盾性的。这是监管当局应该 认真思考的问题, 从而取得利益与风险之间的平衡。

\section{5. 对完善中国金融监管的对策建议}

\section{1. 借助数字技术，加大监管设备的创新}

当前是数字化时代, 大数据、云计算等新兴产业 正在大力占领中国市场, 越来越多的行业都依托于大 数据, 取得了较大的发展。金融业中网上银行在各国 迅速发展, 电子化交易和结算数量极大, 速度极快, 网络系统错综复杂, 一旦出现错误, 损失将不可估计, 然而金融业的对外开放, 更是涉及到全球金融业, 仅 仅依托于以前的网络金融监管、人员监管显然已经不 再适用。大数据是金融监管很好的一个手段, 依托于 大数据巨量的数据资料, 不断创新监管设备, 不仅可 以节约监管成本, 更能依据监管数据, 更好的预测金 融业的发展趋势, 进一步创新监管措施。

\section{2. 加强金融监管协调机制}

完善、健全的金融监管体系是金融业稳健经营的 主要保障, 合理的协调机制是金融开放和监管的前提。 虽然巴赛尔委员会、国际证券会委员会组织等全球性 组织制定颁布了大量的监管法律条文，但对于金融业 对外开放, 中国参与金融监管合作和自身监管协调仍 不充分。我国作为发展中的大国, 金融业实行对外开 放对全球的影响可谓立竿见影, 加强本国政府与监管 机构、各监管机构之间以及参与国际、区域和双边等 多层次的金融监管合作和确立协调机构是我们义不 容缓的事情。

\section{3. 加强混业监管}

中国实行金融对外开放，打破了中国原有的金融 组织结构, 金融业务变得更加复杂, 金融业中行业与 行业之间业务和组织构架难以区分, 分业监管的模式 产生的监管重合或监管真空, 给金融业的发展带来了 许多的阻碍。加强混业监管, 与国际进行充分的协调, 对金融业进行统一监管, 避免监管真空和监管“浪费”, 节约成本的同时更好的为金融业对外开放提供强有 力地支持。

\section{4. 加强对金融监管人员素质的培养，权衡 利益与风险之间的关系}

监管政策的制定和监管理念归根究底是监管者 的自身对金融业发展所做出的反映，因此问题的根本 在于对监管者素质和知识的培养。经济学中认为, 每 一个人都是理性的, 都会为自己寻求利益, “二王案”

(证监会发审委工作处副处长王小石利用职务之便 非法收受贿赂以及国家开发银行副行长王益 “双规” 所涉及的案件) 之类的案件, 也反映了监管者的权利 垄断和腐败问题。在利益面前, 一些监管者看不到风 险爆发的严重性, 以掩盖事实或从轻甚至免除处罚的 “包庇”行为屡屡可见。监管者不能只是 “严于律人” 或 “宽以待已”, 一个缺乏素质和监督的监管系统是 危险的, 为了避免风险的发生, 就必须加强对监管者 的素质教育, 权衡利益与风险之间的平衡。

\section{5. 加强对金融监管人员素质的培养，权衡 利益与风险之间的关系}

金融业对外开放应与国内外进行充分的协调，具 备一定的条件后才能开始，在金融业政策开始实行之 时, 相应的金融监管政策也应该随之跟上步伐。金融 监管往往是在金融行业发生某种变化时, 监管者发现 问题后，才会制定相应的监管政策，但金融业对外开 放是会产生很多问题的，过快或者过慢实行都会给金 融和经济带来不良的后果。所以金融监管必须及时跟 上金融开放的节奏, 金融业开放的时机和力度又必须 有所把握, 只有这样, 金融业的开放才能的得到保障。

\section{6. 结论}

毫无疑问，扩大金融业对外开放是我国实行走出 去和引进来的重要决策, 也是我国发展的当务之急。 金融监管为金融业的发展提供支持, 不断发现金融监 管问题并进行整改是监管机构为金融业对外开放提 供的最有利的贡献。在新政策背景下, 2018 年-2019 年金融业对外开放和中国金融监管都有了快速的发 展, 不管是在银行行业或者是保险行业, 中国都引入 了大量的外资机构和允许扩大金融业务, 证券行业尽 管受到贸易的摩擦也呈现出欣欣尚荣的状态。这是新 一轮金融业开放的成果。金融监管区域不断扩大，分 业监管体系受到压力, 以及数字时代带来的冲击, 都 为金融监管现有的模式带来挑战与影响。金融业对外 开放脚步不断加快, 金融监管需要为其提供政策保障, 改善监管协调机制、加大监管创新和充分利用数字科 技, 在把握开放力度下保障金融市场的稳健运行和健 康发展。

\section{REFERENCES}

[1] Weller, C.E. (2001) Financial Crises After Financial Liberalisation: Exceptional Circumstances or Structural Weakness?. J. Journal of Development Studies., 38(1): 98-127. 
[2] Glick, R., Hutchison, M. (2005) Capital controls and exchange rate instability in developing economies. J. Journal of International Money \& Finance., 24(3): 387-412.

[3] Jeanne, O. (2012) Capital Flow Management. J. American Economic Review., 102(3): 203-206.
[4] Melecky, M., Podpiera, A.M. (2013) Institutional structures of financial sector supervision, their drivers and historical benchmarks. J. Journal of Financial Stability., 9(3): 428-444. 